2008

\title{
The Corporate Social Responsibility Movement as an Ethnographic Problem
}

John M. Conley

Cynthia A. Williams

Osgoode Hall Law School of York University, cwilliams@osgoode.yorku.ca

Follow this and additional works at: http://digitalcommons.osgoode.yorku.ca/all_papers

\section{Repository Citation}

Conley, John M. and Williams, Cynthia A., "The Corporate Social Responsibility Movement as an Ethnographic Problem" (2008). All Papers. Paper 51.

http://digitalcommons.osgoode.yorku.ca/all_papers/51 


\title{
The Corporate Social Responsibility Movement as an Ethnographic Problem
}

\author{
John M. Conley, University of North Carolina School of Law
}

Cynthia A. Williams, Osgoode Hall Law School, York University

Paper Prepared for Wenner-Gren Foundation Seminar on"Corporate Lives,' School for Advanced Research, Santa Fe, NM, August 2008

\section{Introduction}

Over the past decade, the business world has devoted an extraordinary amount of attention to the concept of "corporate social responsibility." "CSR" derives from the idea that the responsibility of a corporation extends beyond the traditional AngloAmerican objective of providing maximal financial returns to its shareholders. Instead, CSR proponents have argued, the legitimate concerns of a corporation should include such broader objectives as sustainable growth, equitable employment practices, and longterm social and environmental well-being. Corporate managers, they contend, should consider not only their shareholders in making their decisions but also a variety of “stakeholder” constituencies, including employees, residents of communities affected by corporate activities, governments, and organizations advocating for various social and environmental interests.

CSR is now the focus of a well-defined and energetic movement that has manifested itself in a variety of ways. It is, in Sally Engle Merry’s (2006a:28-29) phrasing, a global reform movement that represents a "corner” of globalization itself. On the legal front, it has thus far had limited impact in the United States; American corporate 
law is still largely focused on shareholder value. In Europe and the United Kingdom, however, the CSR movement has been a major factor in moving the theory and practice of corporate law in the stakeholder direction. Beyond these legal developments, the influence of the CSR movement can also be seen in the voluntary behavior of corporations. Many of the world's largest companies have started to produce social and environmental reports in addition to their required financial reports. Many of the same companies have also altered the way they interact with their stakeholders, especially the nongovernmental organizations (NGOs)-environmental, labor, human rights, and other issue-advocacy organizations - that are often their most strident critics. NGOs now help corporations to identify issues, produce and audit reports, conduct “dialogs” with diverse stakeholders throughout the world, and address specific problems. Instead of adversarial standoffs, one now often sees "engagement” and "partnerships."

A critical question is whether these developments will prove to be nothing more than trends in corporate communication, what the sociologist Ronen Shamir (2004a:675) has called “an impression management strategy designed to improve [corporations'] image and enhance their market competitiveness.” We have heard corporate CSR people ask, "What should we be doing to demonstrate we're a socially responsible company?" Others have spoken of the need "to avoid sending different messages to different parts of the world" and, perhaps most tellingly, have characterized themselves as "stewards of our reputation.” Against this background, do CSR activities reflect, or at least portend, an important shift in corporate managers' perceptions of their social responsibilities, or are they simply efforts at public relations, reputation building, and the preemption of onerous legal requirements? 
The many participants in these activities comprise the contemporary CSR community. They include a new class of CSR professionals within for-profit companies; yet another new class of outsiders who consult with companies and audit their nonfinancial reports; the lawyers who advise corporations on whether they may or must attend to stakeholder interests; "socially responsible investors" who purport to put their money where their social consciences are; those who work for and on behalf of NGOs; government officials worldwide whose mandate covers social and environmental issues; and their counterparts at transnational agencies such as the World Bank Group.

Shamir (2004a:669) has characterized CSR as a "field of action" shaped by the interplay between popular pressure on corporations and the latter's response to that pressure. The field is the site of a contest between "those players who associate the term 'responsibility' with an ever-increasing set of moral duties" and "corporations and a host of other players who tend to associate the concept of CSR with a voluntary and altruistic spirit and insist, at best, on self-regulatory schemes” (ibid.671). In this paper we report on an ongoing project in which we endeavor to treat the CSR movement as a “deterritorialized” ethnographic site (Merry 2006a:28). We are investigating the meaning of CSR to people in corporations and their various stakeholders, examining the ways in which CSR is practiced, and assessing the potential impact, within a company and beyond, of a firm's undertaking CSR initiatives. It is difficult to observe people "doing” CSR in a physical sense; there is no ready equivalent to a kula voyage. Nonetheless, through participant observation of public CSR events, interviews with many kinds of CSR protagonists, and discourse analysis of CSR texts, we are developing a picture of the complex culture of CSR. By “culture,” we mean, following Merry (2006a:15), the shared 
(if contested) beliefs, values, ways of knowing, practices, habits, language, and other resources that are available to participants as they strive to define CSR, advance or resist particular visions of CSR, and compete for the various sources of power that CSR engenders.

\section{CSR as an Anthropological Problem}

Theoretically, our work builds on a growing body of research in anthropology and sociology concerning various aspects of globalization and the global economy. At the highest level of abstraction, our work is rooted in economic anthropology. In reaction to the political and legal hegemony of neoclassical economics, contemporary anthropology characterizes Western economic thought as a case of "ethnoeconomics”: a cultural practice, a modeling of material life (Bird-David 1997). If so, then CSR can usefully be studied as an aspect of that practice, as discourse and behavior that promise to mitigate some of neoclassicism's harsher effects while reaffirming its core values.

More specifically, the anthropology of development has posed a number of number of fundamental questions about neoclassicism's interaction with other cultural systems, several of which are directly relevant to CSR. Arturo Escobar (1997:503) asks, “In what ways was the 'Third World' constituted as a reality for modern expert knowledge?” CSR is a case study in the operation of modern expert knowledge upon the economic and cultural Other. Escobar (ibid.) also asks whether the entire concept of “development,” including the currently ascendant "sustainable development," is an “invention, that is, a historically singular experience that was nether natural nor 
inevitable, but very much the product of identifiable historical processes.” Sustainable development is a taken-for-granted but poorly-defined value that lies at the core of CSR, raising the related questions of what it means to CSR enthusiasts and how it became so naturalized. Finally, Escobar (ibid.) questions development’s “map,” “a view of the apparatus of expert knowledge" that organizes "the simultaneous production of knowledge and power.” As will be seen, CSR experts not only acknowledge, but take pride in "mapping" their diverse stakeholders, all but demanding an analysis of this particular instance of knowledge and power begetting each other.

Although there is little work in anthropology dealing directly with CSR, research on a number of related corporate issues is relevant. In his already-classic Seeing Like a State, James Scott (1998) was among the first to observe that the multinational corporation was succeeding to many of the functions and powers that had previously been monopolized by nation-states. Following Scott in his own work on oil company enclaves in Africa, James Ferguson (2005:377) concludes that "global capitalism just does what the modernizing development state once did—only to a larger degree.” “According to the mythology of neoliberal globalization,” Ferguson (ibid.:379) contends, the result of these activities was supposed to have been a "structural adjustment" that would liberate "a newly vital 'civil society”" and ultimately bring about "a new sort of 'governance' that would be both more democratic and more efficient.” Instead, Ferguson finds, the result has been an "outsourcing" of governmental functions to NGOs that has “decapitated” African governments.

This "new governance" has also been a major theme in recent scholarship in law and political science (Scott 2003; Slaughter 2003). According to new governance 
theory, the democratic state is in the midst of a shift to a "post-regulatory" model characterized by a weakening of top-down governmental regulation of in favor of a diffusion of rights and responsibilities among governments, private companies, NGOs, and other interested parties. The essence of the post-regulatory state, captured in the linguistic shift from government to governance, is the diffusion of regulatory power among networks of state and non-state actors that transcend national boundaries. This is precisely what the CSR movement seems to be demanding and, up to a point, to be producing. But critics of the new governance question the processes_or lack thereoffor selecting those who will share this diffused power, and ask how these people and institutions will be held accountable (e.g., Bendell 2005). These turn out to be questions that CSR protagonists are asking of themselves, with no consensus about the answers. In many respects, then, understanding the realities of CSR provides a unique opportunity to test new governance theory against practice.

Anthropologists have done extensive work on the non- and intergovernmental organizations and networks that are central actors in the practice of the new governance (see generally Cowan 2006). Often, as in Annelise Riles’s work on international human rights lawyers, these organizations are treated as elites or "expert cultures,” defined—and empowered--by distinctive “knowledge practices” (Riles 2006:53). Most relevant to our project has been Merry’s (2006a, 2006b) work on the international women’s rights movement.

Methodologically, Merry has applied the concept of multi-sited or derritorialized ethnography to a global reform movement, an approach we have emulated on a more modest scale. Also, as previously noted, we have followed a similar 
understanding of culture, striving in particular to see CSR as a "global cultural process" involving "transnational culture flows and their relationships to local cultural spaces" (Merry 2006a:19). We believe that the latter concept will be especially salient as we focus on the Equator Principles, which, as explained in the next section, involve the promulgation of transnational human rights and environmental standards and their application in diverse local cultural settings (Szablowski 2007). Finally, we have been sensitized by Merry's writing on the problem of voice in elite transnational reform movements, as when she asks, "Who speaks for culture?” (ibid.:16).

There is also a substantial and rapidly growing anthropological literature on corporations and their activities. Chris Ballard and Glenn Banks (2003), for example, have written of "the anthropology of mining," using the technique of multi-sited ethnography to explore such issues as "the internal structure and politics of mining corporations” (ibid.:290), “mining discourses” (ibid.:292), and the concept of resources as a "curse" on the development of a functional state. In an edited volume, Carl Maida (2007) and his contributors have looked critically at the usually taken-for-granted concept of sustainability, examining its meaning in various "communities of place.” And many anthropologists have investigated specific corporations as ethnographic sites, their approaches ranging from the highly theoretical (Llewellyn and Harrison 2006; Moore 2005; Nafus and Anderson 2006) to the applied (Jordan 2003).

With respect to the study of CSR itself, the work that most directly parallels this project comes from sociology and law. As noted earlier, the sociologist Shamir has identified CSR as a "field of action," which is clearly analogous to an anthropologist’s "site.” He, too, has analyzed CSR as an exercise in the new governance, 
a "conceptual space where various regulatory/disciplinary regimes are pursued and negotiated among a host of players” (Shamir 2004b:659), and has reported on an essentially ethnographic study (Shamir 2005) of CSR activity in Israel that focuses on framing and the construction of meaning. We have been pursuing many of the same themes from a perspective that is explicitly cultural, with a particular emphasis on language. Finally, David Szablowski (2007), a law and society scholar, has done what he terms a "case study" of a Peruvian mining project that has a strong ethnographic component, and that emphasizes the complex interactions between transnational norms and local realities.

\section{Background and Methods of the Project}

For both practical and theoretical reasons, our primary focus has been on discourse: practically, because so much of the "action" of CSR consists of talk; and theoretically, because of the well-recognized "role of language and meaning in the constitution of social reality” (Escobar 1997:501). We have therefore devoted most of our attention to what participants say at CSR community events, what they say in interviews, and what they write in CSR communications. As of this writing, more than four years into the project, we have attended eight major CSR conferences in the United States and Europe. We have watched, listened, occasionally asked questions in public sessions, and conducted follow-up interviews as CSR participants from the various affected sectors gather to debate issues, inform each other, and develop practical plans for action. We have also participated in a month-long online, interactive conference, and have been involved in three "multi-stakeholder dialogs.” We have thus far conducted more than sixty interviews (in the United States, Canada, and Europe) of corporate CSR 
specialists and other executives interested in CSR, consultants of various sorts, lawyers, institutional investors, investment advisors and money managers, government officials, journalists who cover CSR, and representatives from a range of NGOs. We continue to add to the interview corpus, with an evolving focus that is described below.

The interviews have varied widely in content, depending on the background, work, and interests of the subjects. Our approach has been the one that Conley has used in a series of prior projects involving law and business (e.g., Conley and O’Barr 1990; O’Barr and Conley 1992). Working from a general and flexible topic outline, we prompt our interlocutors to set the specific agenda, moving from topic to topic as they see fit, giving various topics such emphasis as they may choose, and commenting freely on outlook and practices. Again following Conley's previous work, in analyzing the interviews and our participant observations of CSR events, we have paid particular attention to the details of discourse, examining closely the ways in which people choose to express themselves. In so doing, we are motivated by the related concerns of linguistic anthropology and conversation analysis: in the former case, an interest in "language as a cultural resource and speaking as a cultural practice" (Duranti 1997:2); and in the latter, the belief that "talk can be examined as an object in its own right” (Schegloff 1992:xviii), because "structure and meaning are 'emergent', created in the process of interaction as people devise strategies for responding to the immediate situation and solving the immediate communicative problems” (Johnstone 2002:108).

For the same reasons, we have also undertaken the qualitative discourse analysis of several CSR reports issued by multinational corporations. In this paper we discuss four such reports, two each issued by ExxonMobil and British American 
Tobacco. Additional analyses are in progress; for the reasons discussed in the next paragraph, we are looking now at multinational banks.

For the first three-plus years of the project, we focused on CSR generally. We have published a series of papers, largely for legal audiences, that provide an overview of our observations and analyses (Conley and Williams 2005) and address such specific questions as the nature and purpose of the corporation (ibid.; Williams and Conley 2005a), the comparative law of CSR (Williams and Conley 2007), the role of corporations in securing and promoting human rights (Williams and Conley 2005b), and the realities of modifying corporate behavior (Conley 2005). For much of the past year we have turned our attention to a specific instance of CSR: the Equator Principles (EPs). The EPs are set of "best practices" adopted by most of the developed world's multinational banks for assessing and mitigating the social and environmental risks of major infrastructure projects that they finance—dams, refineries, port facilities, etc. (Szablowski 2007). We are early in the process of interviewing (approximately two dozen to date) representatives of the banks that make such loans, the corporations that seek them, the large law firms that arrange them, and the governments and NGOs that monitor them. We have also been participant observers at a major EP conference in London attended by bankers, consultants, government officials, and lawyers. With support from a recent grant from the Social Sciences and Humanities Research Council, a Canadian government research organization, we hope soon to be able to expand our research to include ethnographic visits to EP banks and to the sites of some of the projects funded by EP loans-in Merry's terms, to move from the transnational to the local. 


\section{The Look and Feel of the CSR Movement}

A “CSR community” has clearly emerged both in the United States and Europe, with a distinct and evolving repertoire of rituals and language. This reality was vividly illustrated at the outset of the project. In Los Angeles in November 2003, we attended the annual meeting of Business for Social Responsibility, an umbrella organization in the United States that brings together companies ranging from the Fortune 50 to local boutiques, CSR consultants, advocacy groups of many stripes, religious organizations, socially responsible investment advisors, journalists, and an eclectic mix of interested individuals. The group, which numbered approximately 1,000, seemed remarkably homogeneous. At the simplest level, the group looked homogeneous, with virtually everyone affecting a mellow-casual look (a grade less formal than corporate casual). The discourse was uniformly affirming, congratulatory, and therapeutic; process, journey, dialog (as noun or verb), facilitating, verified (on one occasion combined into "facilitated and verified dialogue”), embedding, and message were recurrent terms and dominant themes. Regardless of whether the speaker was the "VicePresident for People and Culture” at a fashion boutique or a tobacco company scientist, we did not hear a single question that was even challenging, let alone hostile. From all available evidence, this was a gathering of believers, a movement in progress. The talk focused on “us,” presumably in reference to the CSR movement.

Despite its egalitarian tone, the movement clearly has its stars. At the BSR gathering, the CSR team from British American Tobacco was at the top of the A-list, at least as judged by audience size and reaction. Their breakout session on "Stakeholder Engagement: Learning from Experience” was the subject of intense anticipation. The 
presentation, delivered by a strikingly diverse four-member panel brought from BAT's locations around the world, to the accompaniment of sophisticated PowerPoint slides, played to a packed room. The question period featured universal praise for BAT's engagement of stakeholders ranging from European health authorities to South African office workers to Central American farmers. When the formal session concluded the audience crowded onto the stage to continue the discussion. To us neophyte observers, that a tobacco company could play such a role had a surreal quality.

A different sense of the CSR movement emerged in February 2005, when we observed a conference in London entitled "Business/NGO Partnerships and Engagement: How To Make Sure Everyone Gets What They Want.” It was considerably smaller than the BSR gathering, with about 200 attendees. Perhaps because of the British venue, it was also considerably more formal, with business suits the order of the day. Other aspects of the gathering exhibited both similarities and differences with the earlier American meeting.

The language was similar in many respects. Indeed, the two key words in the conference title, partnerships and engagement, had figured prominently in the discourse in Los Angeles. Process and dialog were also recurrent words and themes. By contrast, however, the language of affirmation and congratulations that was so prominent in Los Angeles was largely absent in London. This difference was perhaps attributable to the narrower purpose of the London meeting. Whereas the Los Angeles conference had been a big-tent gathering of CSR enthusiasts, the London conference was focused on the nutsand-bolts activity of organizing and managing partnerships in which an NGO advises and monitors a corporation in the area of the NGO's expertise. 
This difference in purpose may also have accounted for a marked difference in tone between the two conferences (although we cannot discount the mere passage of time-perhaps the bloom had come off the communal rose in fifteen months.) Every discussion we heard in Los Angeles was positive, but there was considerable tension in the air at the London sessions. Even when successful partners appeared on stage together to discuss and analyze their arrangements, each side took considerable care to preserve its separate identity. One especially striking pairing involved the executive director of Greenpeace UK and the CEO of the British power company npower. Although the particular "engagement" involved the monitoring of an offshore windmill project, the Greenpeace representative anticipated skepticism about his organization's involvement with a company that also generates nuclear power. He repeatedly stressed that Greenpeace remains a “campaigning NGO,” always ready to take "direct action” in support of its "fairly radical policy positions." Speaking preemptively, he acknowledged "the risk of selling out." Aggressive questions from the floor indicated that others shared his concern.

Another session entitled “When Agreements Do Not Work Out” produced a level of hostility unseen at the Los Angeles gathering. The featured speaker was a former CSR executive from Asia Pulp and Paper (“APP”), an Indonesian company that has been targeted by environmentalists for its alleged destruction of rainforests. He analyzed the company's failed environmental partnership with the World Wildlife Federation ("WWF"). In neutral tones, he discussed the "language barriers" that can arise between NGOs, which speak an "aspirational language," and companies, which must speak a “specific language of performance.” The barrier becomes particularly daunting, he said, 
with respect to the definition of success or failure. He also discussed the inherent difficulties in developing a relationship with an NGO that may have its own stakeholders all over the world: "Who are you actually dealing with?”

During the question period, his remarks elicited an attack from a woman in the audience who worked for the WWF. She asserted that "APP kept on talking while they logged the rainforest," and contrasted APP's behavior with that of other companies with which WWF had engaged. The APP man responded that "the differences between companies on the ground are very small," and arise "on the basis of style of engagement.” He concluded that he was "personally hurt by WWF's failure to make meetings and return calls.”

The point of these details is that they reveal an important distinction between CSR engagement in rhetoric and in practice. At the Los Angeles conference, the CSR movement presented itself as a monolith of like-minded people who engage in a uniformly positive rhetoric. When it comes time to practice the theory, however, as the London conference suggests, CSR practitioners are subject to the same pressures as business and political partners.

A final and striking point is that, at conferences and in interviews, we have observed a convergence of the speaking styles of the corporate and the nonprofit participants in the CSR movement. The corporate participants are entirely comfortable with the rhetoric of the NGO world. But at the same time, NGO executives are now routinely talking about their respective "brands.” Indeed, in one interview, a representative from a well-known environmental organization dismissed a somewhat 
rowdier competitor as "unbranded.” NGO people also regularly discuss adapting the corporate concept of "accountability" to their own organizations, seeking various kinds of "bottom lines" to apply to their activities. And even as they themselves function as stakeholders, they are beginning to acknowledge that they, too, have stakeholders who may have divergent views of the organization's mission.

\section{The Themes of CSR Discourse}

Beyond these issues of look and feel, the content of the discourse at these and other conferences and in our interviews has also been revealing. The sections that follow briefly introduce some of the themes that have been recurrent in our work.

\section{CSR and Voice: Who Speaks for Whom?}

As CSR is practiced, almost everyone purports to be speaking for someone or something else. Corporate employees assert the interests of their employers, which are indeterminate legal fictions. Government representatives speak for constituencies that are usually ill-defined, and sometimes for even vaguer conceptual entities like "the nation.” NGOs almost by definition speak for others' interests: indigenous people, workers, "the environment." What are the bases for these actors' claims to speak for others? How legitimate are they?

CSR participants are aware of this issue, at least on a superficial level. In Los Angeles in 2003, for example, much discussion involved the question of who counts as a stakeholder. Most CSR participants immediately include employees, residents of communities where the company has a significant presence (or "footprint"), and the 
governments of affected locales. Our contacts within corporations, even in the United States, almost always list employees, customers, and community residents as stakeholders. To this list the Los Angeles and London conference participants added, uniformly, "civil society," which tends to be used synonymously with "NGOs."

In all of our observations and interviews, we have heard surprisingly little analysis of how particular NGOs become stakeholders in particular companies. One obvious way is by "campaigning" against the company and then being approached to enter into a "partnership," as in the Greenpeace-npower case just discussed. Others gain de facto stakeholder recognition from a company after campaigning against it, though they are not offered formal partnerships. We have heard of other instances in which companies invited NGOs into partnerships because of their visibility and apparent expertise on particular issues, such as rainforest protection, climate change, or labor rights. Neither in our observations nor our interviews (where we have posed the question directly), however, has anyone set out any explicit criteria for deciding who gets a seat at the stakeholder table. Instead, some have acknowledged that it depends largely on an NGO’s ability to make noise.

The disconnection between transnational elites and local realities has surfaced throughout the project. As we write, news sources report the ramming of a Greenpeace ship by a Turkish fishing boat (Associated Press 2008). During a 2004 World Banksponsored online conference about CSR in small and medium-sized enterprises, a comment by a representative of a Nigerian NGO was both pointed and poignant: the "challenge of being [a] socially responsible SME is not valid when their possibilities of existence [are] close to zero.” 
A related problem is the potential of the CSR movement to inhibit the growth of strong local institutions in places where corporations are "engaged” with NGOs. In some instances, circumventing a corrupt local government is the very purpose of the corporateNGO partnership. But even where the local government (particularly at the regional or village level) is doing its honest best, the partnership's economic and political muscle may make it appear irrelevant. When this happens, a number of our informants have warned, local good government advocates may simply give up. The effects of this are particularly pernicious when the specific work of the partnership (in one example given, insuring that an influx of workers to build a plant did not disrupt local life) is done, the foreigners have largely withdrawn, and the locals are, once again, left to fend for themselves. Far from being strengthened by the activities of the corporate-NGO partnership, local institutions will have atrophied, leaving the community less prepared than ever to deal with the challenges of globalization (compare Ferguson 2005).

\section{What Is "Stakeholder Dialog?”}

Stakeholder dialogs are structured discussions among company participants, advocacy groups and other members of civil society, employees, and community members. The specific goals of the dialogs vary depending on the company and the social issues it faces. In general, though, they have the stated objective of creating a forum and a format for two-way communication. Stakeholders provide information to the company about their concerns while the company has a context outside advertising or formal public relations to express its views about contested social issues. "Engagement" through stakeholder dialog is treated as a great good throughout the CSR movement.

NGOs and socially responsible investors demand it, and, at least in Europe and the U.K., 
governments encourage it, and may even delegate their regulatory roles to such dialogs. Among CSR enthusiasts, dialog with non-shareholders is seen as the process through which the concerns of the powerless are heard.

But even as dialog gives stakeholders a voice in corporate deliberations, it offers companies a way to control the way in which that voice is exercised. This point initially occurred to us during the British American Tobacco presentation at the 2003 BSR conference, when one of the company's representatives described the stakeholder dialog as beginning with the "mapping and classification" of stakeholders. BAT speakers also talked of using consultants to select stakeholder participants by determining "who exactly the key players are”; extensive preparation in order to "systematize” the dialog; achieving “consistency across regions" in order "to avoid sending different messages to different parts of the world"; and being careful to "provide stakeholders with clear parameters to show if the company was really doing what it had committed.”

Equator Principles banks illustrate the same point. The bankers, lawyers, and consultants we have interviewed have all emphasized that each of the original signatory banks had endured an out-of-control NGO campaign; the German bank West LLB, for example, suffered the ignominy of protesters rappelling down the side of its headquarters building and unfurling banners. These same sources have all characterized the EP consultation and reporting process as a way to systematize and control the banks' relations with NGOs and thereby minimize reputational damage. In January 2008, for example, when West withdrew its financing for an Indonesian gold mining project, its action was reported only on obscure NGO websites (e.g., Mining and Communities 2008). 
On the one hand, these approaches are perfectly rational, if not inevitable steps in organizing a potentially chaotic conversation with a host of self-proclaimed stakeholders. But on the other, to organize is to discipline, to control, and to limit. Becoming engaged with a powerful institution comes at a cost (Foucault 1977:222). In the case of the state, to be recognized by it often means to acquiesce in its methods of classification and rules of engagement, to give up a part of one’s autonomy (compare Merry’s (1990) “paradox of legal entitlement”). The same principles may apply to the multinational corporation, a creature of the state that mimics it in many important respects (Scott 1998; Ferguson 2005). From this perspective, what a company like BAT characterizes as the valueneutral "facilitation" of stakeholder dialog can be seen as an exercise in control—control over who participates, how things get said, and, consequently if indirectly, what gets said.

\section{How Serious Are the Participating Corporations?}

Our interviews of corporate CSR specialists and their consultants are providing a window on the day-to-day world of CSR in practice. As might be expected, what we have heard is calmer, more reflective, and sometimes more cynical than what is said in the revival-like atmosphere of a large gathering. Nonetheless, the content is consistent. People think that CSR is here to stay and is effecting a meaningful change in corporate behavior. Both corporate CSR specialists and outside consultants believe that the executives they work for take it seriously. It is widely believed that if a company adopts appropriate processes for talking with stakeholders and reporting its performance then salutary outcomes will ensue. 
Interestingly, the jury of CSR insiders is still out on the economic benefits to be derived from good corporate citizenship. With the exception of those in the socially responsible investment business, we have not heard anyone make a robust claim that CSR can be shown to boost the traditional bottom line. People within companies have discussed positive effects on employee recruitment and retention as well as customer loyalty, but, surprisingly to us, most have made no serious efforts to quantify these perceived benefits. Nonetheless, everyone with whom we have spoken believes that CSR will prove itself to be economically efficient, at least in the negative sense of heading off such things as labor unrest, customer defections, costly environmental problems, and, importantly, government interventions. As far as consumers are concerned, however, every person we have heard or interviewed has agreed with the proposition that they (except for an affluent niche) will not pay more for responsibly-produced products.

Against this background of general corporate optimism, our work has also revealed widespread skepticism. In this view, CSR participation is little more than a show of voluntary reform intended to head off government mandates, preempt NGO attacks, and succor favor with the minority of CSR-conscious consumers. One proponent of this view has described corporate participants in CSR as "struggling to structure it around voluntary self-regulation and to position themselves as authoritative players within it” (Shamir 2004a:655).

The skeptical view was vividly represented in a 2004 report by Christian Aid, a respected British relief agency, entitled Behind the Mask: The Real Face of Corporate Social Responsibility. The report defines CSR as nothing more than "a catch-all term increasingly used by business, which encompasses the voluntary codes, principles and 
initiatives companies adopt in their general desire to confine corporate responsibility to self-regulation.” It characterizes the whole movement as a disingenuous public relations exercise: “corporate enthusiasm for CSR is not driven primarily by a desire to improve the lot of the communities in which companies work. . . Rather, companies are concerned with their own reputations, with the potential damage of public campaigns directed against them, and overwhelmingly, with the desire-and the imperative-to secure evergreater profits." And turning to what we have termed the "CSR community," the report observes that London "is now awash with PR consultants, social auditors, firms providing verification or 'assurance' for companies' social and environmental reports, and bespoke investment analysts all vying for business.”

\section{What is the Role of the NGOs?}

There is evidence from our observations and interviews that even as NGOs develop a more corporate style, their substantive outlook and behavior grow more corporate as well. At the 2005 London conference, the research and advocacy director for SustainAbility, a British consultancy that is one of the most prominent and players in the CSR movement, observed that the nature of NGOs’ power is changing. Traditionally, he said, NGOs sought and exercised power "through confrontation”; now, however, they are "controlling the agenda and defining the choices that are available" to companies facing CSR pressure. NGOs are "no longer just gadflies," he continued, but are "part of the system now." NGO officials acknowledge this, but at the same time worry about the effect on their "brands." Representatives of Greenpeace and other environmental organizations have repeatedly stressed to us the need to avoid complicity in the “greenwashing” of corporate environmental malfeasance. 
Another piece of evidence is NGOs’ growing concern with accountability. For example, a plenary panel at the 2005 London conference was devoted to "NGO accountability... what's being done to create greater transparency?” Transparency is not just a business buzzword, of course, but has long been the pivotal concept in financial reporting. One speaker, from the educational NGO One World Trust, declared that accountability must be "embedded in the NGO, from the top down"- - statement we have heard from and about dozens of corporations. A panelist from Christian Aid acknowledged that "NGOs like Christian Aid are not as accountable as they should be,” decrying NGOs that engage in "horrible company-style CSR presentations.” There was also general agreement that, as NGOs demand that corporations account to their broad stakeholder base, the NGOs must do the same.

But the same discussion also illuminated a number of significant differences between NGO and corporate accountability. An anonymous questioner from the floor argued that NGOs must be wary of demands for accountability, since they are sometimes a pretext for efforts to defang aggressive NGOs and limit their ability to act. The representative of One World Trust made the point that, whereas NGOs are spread out across cultures, accountability is an Anglo-Saxon word and concept: “Accountability doesn’t translate into almost any other language.” He asked what “accountability” could mean in the case of NGOs, arguing that “it's not legitimacy, not democracy, nor transparency.”

Some theorists have analyzed the discourse of social movements in terms of “frames,” or "ways of packaging and presenting ideas that generate shared beliefs, motivate collective action, and define appropriate strategies of action” (Merry 2006b:41). 
NGOs that participate in CSR activities confront a dilemma that is endemic to social movements: framing their ideas in ways that simultaneously appeal to their members' traditions and promote change—-frames, in other words, that allow for both legitimacy and efficacy. To take the example of Greenpeace, its leadership emphasizes its tradition as a "campaigning NGO” with "fairly radical policy positions.” But that same leadership now believes it necessary to enter into corporate partnerships in order to effect change. Can Greenpeace and other NGOs have it both ways?

\section{Analyzing the Discourse of CSR Reporting}

Similar themes can be seen in the written CSR reports that increasing numbers of global companies now publish. These reports are typically glossy, elaborate documents that resemble annual reports to shareholders in their professional production values. Various sorts of specialists are involved in their preparation and "verification." However, they are entirely voluntary, neither their existence nor their format being dictated by governments. Thus, they reflect the considered choices that companies make about how to discuss corporate social responsibility, and their style and content are especially revealing for this reason.

Sharon Livesey (2002a, 2002b), a lawyer and business communication scholar, has recently initiated the critical linguistic analysis of corporate CSR reports. We have also begun work of our own in this area, and describe some of our results below. Livesey's method involves the identification and categorization of "salient themes, metaphors, modes of expression, and argument structures” (Livesey 2002a:321) She draws on Foucault's perspective, emphasizing his belief that "meaning is not fixed; 
rather, it must be constantly reproduced and reconstituted” (ibid.:319). CSR discourse represents such a reconstitution, "the emergence of a new, unstable discursive order, which joins the heterogeneous elements of the distinct domains of economics, environmentalism, and social justice” (ibid.). From the Foucaldian perspective, power can be both a cause and an effect of controlling this emergent discourse. More specifically, as Shamir (2004a:680) has put it, “[t]he bureaucratization and standardization of social responsibility transforms the heretofore politically loaded and morally debated notions of corporate responsibility into a measurable set of indicators that can be exchanged and traded.”

Our first subjects have been the 2003 and 2006 (the most recent available) reports issued by ExxonMobil and British American Tobacco p.l.c. We chose ExxonMobil because it entered the CSR era as perhaps the world's greatest environmental villain following the Exxon Valdez oil spill in 1989. We selected BAT to complement our previous analysis of the public discourse strategies employed by its CSR team, and because of the particular difficulties faced by a tobacco company holding itself out as socially responsible. In very different ways, the two companies' reports are the embodiment of Shamir’s (2004a:680) “bureaucratization and standardization of social responsibility."

From the very beginning, the short, succinct, and glossy ExxonMobil 2003 report blends the social and the economic, the 'soft' and the 'hard', the rhetoric of care and the rhetoric of analysis. The single-page introductory letter from Chairman and CEO Lee R. Raymond states as the company's the goal the creation of "sustainable shareholder value” (ExxonMobil 2003:1). This simple yet powerful phrasing merges the traditional, 
narrowly economic vision of corporate fiduciary responsibility with the loosely-defined notion of sustainability, with all of its connotations of broader social and environmental responsibility. But the next two paragraphs redefine social responsibility in primarily economic terms, and disclaim the company's ability to exert substantial influence in the non-economic sphere (ibid.):

However, we cannot be all things to all people ... our primary responsibility to society is to do our job well-providing the world with abundant, affordable energy in a safe, reliable and environmentally responsible manner.

Many other forces-cultural, political and environmental-have an impact on society that is greater than ours.

Finally, the chairman states that even ExxonMobil's "wider involvement in society” will be governed by 'hard' analysis, the "rigorously applied management systems” that mark its core endeavors: "Our approach to corporate citizenship reflects our scale and the disciplined approach we take to all aspects of our business” (ibid.)

The remainder of the 41-report is a detailed playing-out of these themes. The illustrations (which are found on every page) are a striking combination of colorful graphs and charts and photographs of children, tigers, and ExxonMobil employees of every race and many nationalities. In the text, disciplined management and analysis are repeatedly described as the keys to ExxonMobil's social accountability. The "Operations Management Integrity System” is the critical “framework for meeting [ExxonMobil’s] commitments to the highest operational standards of safety, health and environmental 
protection"; under this system, “[a] broad range of factors is analyzed, including economic, environmental and social” (ibid.:3) In the environmental sphere, OIMS is augmented by "Environmental Business Planning” (ibid.:12), which helps the company "to prevent incidents" (ibid.:13). Quantitative "performance indicators" are used to track environmental progress (ibid.). ExxonMobil brings a new and literal salience to the notion of micro-management, employing “'molecule management' to yield high-value products while improving energy efficiency and lowering emissions" (ibid.:14). Even the air is systematized, with emissions being "most effectively managed at the point of discharge” (ibid.).

Greenhouse gases and climate change are the subject of a more complex and ambiguous rhetoric. The discussion begins with a qualified acknowledgment of the problem: "We recognize that the risk of climate change and its potential impacts on society and ecosystems may prove to be significant” (ibid.:9). The essence of the response is consistent with the rest of the report: "to take sensible, economic actions now to improve efficiency and reduce future global emissions” (ibid.). But the application of the management-based logic seen elsewhere is complicated by the absence of appropriate discourse structures, there being "currently no commonly accepted methodology for accounting for greenhouse gas emissions” (ibid.:15). One of the few appeals to hard fact in this section of the report is the statement that it is really someone else's problem: “developing countries represent only 25 percent of the global economy and yet produce almost 50 percent of the world's carbon dioxide (or carbon) emissions," and are likely to account for 80 percent of the carbon increase in the next 20 years (ibid.). 
ExxonMobil’s 2006 report carries the quantitative discourse of science even further. Consistent with the chairman's initial statement of the company's "rigorous approach to corporate citizenship” ( ExxonMobil 2006:3), numbers are everywhere: a dense page of "citizenship performance data" (ibid.:5); another with nine different measures of "engagement activities by group" (ibid.:5); and constant quantification of money spent and spills and injuries reduced. Even the preservation of a twenty-acre wetland gets mentioned (ibid.:23). One wonders if the numbers bring helpful precision to readers, or if the overall effect is numbing.

As in 2003, the qualitative aspects of the 2006 report present a sometimes jarring rhetorical juxtaposition of control and powerlessness. In its approach to CSR, for example, the company claims near-omniscience: "Our efforts are guided by in-depth scientific understanding of the environmental impact of our operations, as well as by the social and environmental needs of the communities in which we operate" (ibid.:14). Even the complexities of human rights yield to analytical rigor, as the report also provides "an example of how we manage and respond to potential human rights issues" (ibid.:41)(emphasis added).

But there are also assertions of helplessness. Here again, climate change "remains an extraordinarily complex area of scientific study,” raising a risk that "could prove to be significant" (ibid.:3). On the social front, on the question of domestic partner benefits, the company defers to country-by-country legal definitions and "provides coverage to spouses — whether heterosexual or homosexual — where a legally recognized spousal relationship exists. . In the United States, we have adopted the definition of spouse used in federal legislation, which has the effect of limiting coverage to heterosexual couples" 
(ibid.:29)(emphasis added). The result of this passive approach, of course, is that the company is unlikely to have to provide same-sex partner benefits in the U.S. at any time in the foreseeable future, since any definitional changes will almost certainly be made at the state level.

The 2003 BAT document is very different in appearance. It is a dense, sprawling report, with 158 pages of compact text and few illustrations. Its content exhibits both similarities to and differences from the approach taken by Exxon Mobil. In his singlepage introduction, BAT chairman Martin Broughton stresses, as ExxonMobil does, the primacy of economics as a motivation for CSR: "Corporate social responsibility is integral to our approach to the management of our business globally and to building long term shareholder value” (ibid.:3).

Elsewhere on the same page, however, the discourse of traditional financial management yields to the alternative 'soft' discourses of communication and feelings. For example, whereas the sentence just quoted is the only reference to shareholders in the chairman's letter, there are eight mentions of the open-ended, contested category of "stakeholders." There is repeated emphasis on the goal of "dialogue” with these undefined stakeholders_- “stimulating discussions, as stakeholders share their views, concerns, criticisms and indeed some praise.” This communicative process can evoke emotional responses, as when the chairman acknowledges that "[i]t is disappointing that we still encounter reluctance amongst the tobacco control and public health communities to engage in dialogue.” Nonetheless, BAT’s “doors remain open” to “stakeholders in these groups” as BAT strives to show by action “that we mean it.” Presumably, any 
representative of these interests who chooses to join the dialog thereby becomes a stakeholder, which further highlights the indeterminacy of that category.

Apparently something has changed. In 2006, BAT adopted the strategy of "reporting more briefly this year than previously ... taking a little time out to review our reporting, with the aim of moving to a Sustainability Report next year" (British American Tobacco 2006:1; the Sustainability Report is not available as of June 1, 2008). In a move toward the rhetoric of accounting, the chief executive states that while "completeness and responsiveness are as important as ever, we recognise that these should not mean reporting each year on all issues that could be relevant to stakeholders, but that the principle of materiality should be considered more fully” (ibid.).

Despite its much-abbreviated (32 generously-spaced pages) format, the 2006 report also goes back and forth between hard and soft discourses. Under the heading of "our performance," it provides concise, bullet-point-laden statements of "action” and "response” in such categories as "Youth smoking prevention,” "Harm reduction,” and “Secondary supply chain.” Harm reduction is especially interesting, as the company promises continuing efforts to "bring to market a new generation of tobacco products [primarily "Swedish snus," a kind of dipping tobacco] that meet consumer appeal and will, over time, be recognized by scientific and regulatory authorities as posing substantially reduced risks to health” (ibid.:6). But, just as in 2003, BAT employs a rhetoric of surprise and hurt at the failure of health authorities to meet it halfway: "we are working to improve our engagement with external scientists"; "We believe there is no rational justification for continuing to bar smokers from choosing a less hazardous 
alternative to cigarettes”; "Regrettably, the Chief Executive [of Cancer Research UK] declined to meet us"(ibid.).

The major change from 2003 is the apparent fall from primacy of stakeholder dialog: "In our previous Reports, we have focused on what our stakeholders expect from us. For this summary Report, we have taken a different approach.” In 2006, the emphasis is on "the thoughts and opinions gathered in the dialogue," not "reporting against each individual session.” The voice of stakeholders, in other words, has become even further attenuated. Now BAT not only selects the stakeholders and systematizes the discourse, but distills its contents.

It is difficult to predict what, if any, practical changes this shift in listening and reporting practices portends. Will BAT will pay greater attention to its social and environmental performance? Will the downgrading of stakeholder dialog cost the company its status as a perceived (if improbable) CSR leader? Or will the new reporting strategy, if and when it emerges, set a new standard for reputation management?

A final point about reporting is the role of external "assurance," the CSR version of financial auditing by certified public accountants. Most CSR reports by major corporations end with an opinion letter from an organization such as Bureau Veritas (BAT 2006) or Lloyd's Register Quality Assurance (ExxonMobil 2006). In general appearance and form, they are strongly evocative of financial auditors' opinion letters, and thus send a message about standards and rigor. But their content is stunningly vague. In the case of ExxonMobil, Lloyd's concludes, for example, that the company "has processes in place that ensure sites that contribute to safety, health, and environmental 
metrics understand corporate reporting obligations"; and that the company's system "is effective in delivering safety, health, and environmental indicators that are useful for assessing corporate performance.” Similarly, Bureau Veritas finds that "the information presented in [BAT's] Summary Report is reliable and objective, and presented in a clear and understandable manner"; and that the report "addresses material issues identified through stakeholder dialogues in previous cycles.”

On reflection, it is hard to see how it could be otherwise. It would be difficult for an "auditor" to be especially substantive when the bulk of what is reported is process. Despite a great deal of talk about emerging CSR "metrics,” the things that command attention among those we have observed and interviewed are, as we have noted above, such intangibles as dialog, the embedding of CSR "in the corporate DNA," and embarking on journeys. While the assurance companies play an important role in legitimizing the self-regulation that is CSR, they appear to provide little that would be of value to a skeptical outsider, whether a "campaigning NGO" or a hard-headed investor.

\section{Conclusions}

At this point in the project, three major theoretical themes have emerged. All three are prominent in the anthropological literature about global movements and multinational corporations.

The first involves the related—indeed inseparable—issues of voice and transnational elites. At almost every turn in CSR practice, someone else speaks for the local communities that are its presumed beneficiaries. These communities are extraordinarily diverse. They include resource sites in the developing world, emerging- 
economy locales to which manufacturing is outsourced, and places in the developed world that used to host the outsourced facilities. Most often, such communities are spoken for by NGOs. These NGOs may have local connections, but in most cases it is only the well-known transnational brands that can get the attention of multinational corporations.

The issue of voice is becoming especially salient in our early work on the Equator Principles. EP banks require companies seeking loans for major projects to commission environmental and social impact assessments. These are typically contracted out to consulting firms that employ a range of experts from engineering to anthropology. It is also common for major NGOs to be invited in as watchdogs. The voices of affected individuals, even if they are heard in the first instance, must survive several layers of interpretation and reporting by these representatives of transnational financial and knowledge elites.

As new governance critics point out, and as NGO representatives readily acknowledge, this reality raises profound questions of legitimacy and accountability. Do particular NGOs get selected to "engage" with corporations because of their ability to give legitimate voice to otherwise powerless interests? Or is it because the corporations value their recognizable brands and trust them not to behave too badly? And if NGOs do become complicit in greenwashing, who will know? Who is watching the watchdogs? It may be that "authentic" mid-level institutions will emerge, local enough to "speak for culture” yet with enough transnational clout to be accepted by companies as engagement partners. But at this stage in the history of CSR, the practical answer may be that there are no obvious alternatives to the current state of affairs. 
The second major theme is the time and energy that corporations devote to the management of CSR discourse. Their efforts include the "mapping" of stakeholders, the administration of stakeholder dialogs and NGO engagements, the preparation of CSR reports, and the public discussion of it all. Regardless of what they may or may not be doing on the ground, corporations are wholly committed to the process of CSR talk, and to talking about that talk. Corporate decision-makers clearly realize that imparting order to a potentially chaotic discourse is a tangible source of power as they seek to mange their companies’ reputations and preempt “hard” action by governments.

This leads to the final theme: the impact of the CSR movement on the nationstate. Even rich, stable, and powerful Western states seem to have limited ability to control the behavior of multinational corporations and, more generally, global capital. Nation-by-nation jurisdiction over corporations is diminished as tangible assets are sent “offshore” and wealth derives increasingly from evanescent intellectual property. At the same time, treaties and "international law" not backed by the threat of force are no more effective than they have ever been.

The CSR movement may be a perfect fit for this hard law vacuum. To the extent that it is perceived to be a meaningful response to social and environmental problems, it dissuades governments from even the effort at regulation. As a devolution of regulatory power to the formerly-regulated, it accords well with the currently ascendant theory of new governance. And to the extent that CSR is persuasive to consumers, it also serves to head off market discipline of irresponsible companies, however unlikely that may be. 
This skepticism is not to condemn CSR out of hand, though. The movement remains a work in progress. At its best, it promises a corporate decision making process in which managers think and talk openly about social and environmental issues and then tell the world what they did and why. At its worst, it is nothing more than an elaborate public relations charade in which companies perform certain prescribed rituals but continue to do business as usual. But it may be even worse than business as usual, as the effect of the rituals may be to co-opt critics, preempt regulation, and mislead consumers.

\section{RFERENCES}

Associated Press. 2008. Turkish Fishermen Ram Greenpeace Ship. MSNBC.com, May 30, 2008, available at www.msnbc.msn.com/id/24893806/.

Ballard, Chris, and Glenn Banks. 2003. Resource Wars: The Anthropology of Mining. Annual Review of Anthropology 32:287-313.

Bendell, Jem. 2005. In Whose Name? The Accountability of Corporate Social Responsibility. Development in Practice 15:362-374.

Bird-David, Nurit. 1997. Economies: A Cultural-Economic Perspective. International Social Science Journal 154:463-476.

British American Tobacco. 2003. Social Report 2002/03. . 2006. Social Reporting: 2006 Progress and Review.

Conley, John M. 2005. Changing Corporate Behavior in a Socially Responsible Direction Center for Progressive Reform Perspectives Series (2005), available at http://www.progressiveregulation.org/perspectives/corp_behav.cfm

Conley, John M., and William M. O’Barr. 1990. Rules versus Relationships: The Ethnography of Legal Discourse. Chicago: University of Chicago Press.

Conley, John M., and Cynthia A. Williams. 2005. Engage, Embed, and Embellish: Theory versus Practice in the Corporate Social Responsibility Movement. Journal of Corporation Law 31:1-38.

Cowan, Jane K. 2006. Culture and Rights after Culture and Rights. American 
Anthropologist 108:9-24.

Duranti, Alessandro. 1997. Linguistic Anthropology. Cambridge, UK: Cambridge University Press.

Escobar, Arturo. 1997. Anthropology and Development. International Social Science Journal 154:497-516.

ExxonMobil. 2003. Corporate Citizenship Report (May 2003). . 2006. 2006 Corporate Citizenship Report.

Ferguson, James. 2005. Seeing Like an Oil Company: Space, Security, and Global Capital in Neoliberal Africa. American Anthropologist 107:377-382.

Foucault, Michel. 1977 (orig. 1975). Discipline and Punish: The Birth Of Prison. Trans. Alan Sheridan. New York: Pantheon Books.

Johnstone, Barbara. 2002. Discourse Analysis. Malden, MA: Blackwell Publishing.

Jordan, Ann T. 2003. Business Anthropology. Prospect Heights, IL: Waveland Press.

Llewellyn, Nick, and Alan Harrison. 2006. Resisting Corporate Communications: Insights into Folk Linguistics. Human Relations 59:567-596.

Livesey, Sharon. 2002a. The Discourse of The Middle Ground. Management Communication Quarterly 15:313-352. . 2002b. Transparent and Caring Corporations? A Study of Sustainability Reports by The Body Shop and Royal Dutch/Shell. Orgnaization and Environment 15:233-261.

Maida, Carl A. (ed.). 2007. Sustainability and Communities of Place. New York: Berghahn Books.

Merry, Sally Engle. 2006a. Human Rights and Gender Violence: Translating International Law into Local Justice. Chicago: University of Chicago Press. 2006b. Transnational Human Rights and Local Activism: Mapping the Middle. American Anthropologist 108:38-51. . 1990. Getting Justice and Getting Even: Legal Consciousness Among Working-Class Americans. Chicago: University of Chicago Press.

Mining and Communities. 2008. Big Banker Withdraws Finance from Indonesian Mine. January 17,2008 , available at http://www.minesandcommunities.org/article.php?a=8397.

Moore, Fiona. 2005. Transnational Business Cuktures: Life and Work in a Multinational Corporation. Burlington, VT: Ashgate. 
Nafus, Dawn, and Ken Anderson. 2006. The Real Problem: Rhetorics of Knowing in Corporate Ethnographic Research. EPIC 2006:244-258, available at www.anthrosource.net.

O’Barr, William M., and John M. Conley. 1992. Fortune and Folly: The Wealth and Power of Institutional Investing. Homewood, IL: Business One Irwin.

Riles, Annelise. 2006. Anthropology, Human Rights, and Legal Knowledge: Culture in the Iron Cage. American Anthropologist 108:52-65.

Schegloff, Emmanuel A. 1992. Introduction. In Gail Jefferson (ed.), Harvey Sacks, Lectures on Conversation, v. I (pp. ix-lxiv). Cambridge, MA: Blackwell Publishers.

Scott, Colin. 2003. Regulation in the Age of Governance: The Rise of the Post Regulatory State. National Europe Centre Paper No. 100, Australian National University, June 6, 2003, available at www.anu.edu.au/NEC/publications.php.

Scott, James C. 1998. Seeing Like a State: How Certain Schemes to Improve the Human Condition Have Failed. New Haven, CT: Yale University Press.

Shamir, Ronen. 2004a. The De-Radicalization of Corporate Social Responsibility. Critical Sociology 30:669-688. . 2004b. Between Self-Regulation and the Alien Tort Claims Act: On the Contested Concept of Corporate Social Responsibility. Law \& Society Review 38:635-664. . 2005. Mind the Gap: The Commodification of Corporate Social Responsibility. Symbolic Interaction 28:229-253.

Slaughter, Anne-Marie. 2003. Global Government Networks, Global Information Agencies, and Disaggregated Democracy. Michigan Journal of International Law 24: 1041-1094.

Szablowski, David. 2007. Transnational law and Local Struggles: Mining, Communities and the World Bank. Oxford, UK and Portland, OR: Hart Publishing.

Williams, Cynthia A., and John M. Conley. 2005a. An Emerging Third Way? : The Erosion of the Anglo-American Shareholder Value Construct. Cornell International law Journal 38:493-552. . 2005b. Is There an Emerging Fiduciary Duty to Consider Human Rights? University of Cincinnati Law Review 74:75104. 2007. Triumph or Tragedy? The Curious Path of Corporate Disclosure Reform in the U.K. William \& Mary Environmental Law and Policy Review 31:317-361. 
